\title{
Gershkov, Alex and Benny Moldovanu: Dynamic allocation and pricing: a mechanism design approach
}

\section{Marco LiCalzi}

\section{Journal of Economics}

ISSN 0931-8658

Volume 117

Number 2

J Econ (2016) 117:181-183

DOI 10.1007/s00712-015-0463-3
Vol. 117 No. 22016

\section{Journal of Economics}

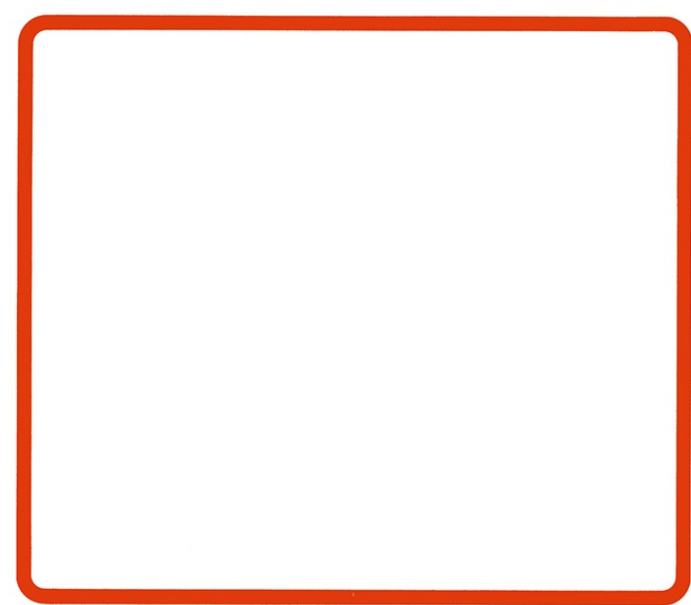

in Springer 
Your article is protected by copyright and all rights are held exclusively by SpringerVerlag Wien. This e-offprint is for personal use only and shall not be self-archived in electronic repositories. If you wish to self-archive your article, please use the accepted manuscript version for posting on your own website. You may further deposit the accepted manuscript version in any repository, provided it is only made publicly available 12 months after official publication or later and provided acknowledgement is given to the original source of publication and a link is inserted to the published article on Springer's website. The link must be accompanied by the following text: "The final publication is available at link.springer.com". 


\title{
Gershkov, Alex and Benny Moldovanu: Dynamic allocation and pricing: a mechanism design approach The MIT Press, Cambridge, 2014. Hardback, £24,95, 195pp
}

\author{
Marco LiCalzi ${ }^{1}$
}

Published online: 7 November 2015

(C) Springer-Verlag Wien 2015

This is the ninth volume in the Arne Ryde Memorial Lecture Series. This timehonored initiative brings onto paper thought-provoking lectures at the edge of the current research.

The goal of this book is to demonstrate how the study of revenue management may be enriched when taking the perspective of mechanism design. Traditionally, the former deals with nonstrategic agents arriving over time, and assumes complete information about their characteristics. Its aim is to derive dynamic pricing policies, including decisions about inventory size and composition, for maximizing revenue or, sometimes, efficiency. Mechanism design, on the other hand, presumes that agents are privately informed and considers the limitations that this imposes on implementable policies. By bringing the techniques of mechanism design to bear on a few topical problems of revenue management, Gershkov and Moldovanu open a path towards making it more realistic, and suggest that mechanism design is ripe to attack a new field.

The book is organized in six chapters. The first is a clear and exhaustive summary of its content, carefully describing both the models studied in each chapter and the results obtained. Table 1.1 on p. 8 gives a bird's eye view. The next four chapters deal with distinct (but related) variants of the following problem: a set of heterogeneous items must be assigned to a sequence of randomly arriving agents with privately known characteristics. The agents are short-lived, meaning that they cannot fake a later arrival and manipulate the timing of their purchase. The sixth and last chapter assumes longlived agents and provides a miscellaneous collection of simple examples and short results.

\footnotetext{
Marco LiCalzi

licalzi@unive.it

1 Università Ca’ Foscari Venezia, Venezia, Italy
} 
As part of a Lecture Series, the volume is meant to be neither a textbook nor a full monograph. The four central chapters rely on research published elsewhere. However, by revisiting their own research and juxtaposing it in one place, Gershkov and Moldovanu offer us a convincing case that the combination of revenue management and mechanism design provides a powerful approach to tackle a variety of problems. The last chapter, more varied in content as well as less systematic, is a tantalizing invitation to push the frontier even further. Each chapter is enriched with a review of the literature and, in the spirit of the best lecturing, almost all theoretical results are illustrated by sharp and effective examples. Here follows a short description for the content of each main chapter.

Chapter 2 (Sequential assignment of heterogeneous objects) studies efficient, individually rational and budget-balanced mechanisms when agents have one-unit demand and private information. The main trade-off is whether assigning an object today or in the future. The efficient dynamic allocation under complete information is well known. After introducing private information and assuming quasi-linear utilities, it is shown that there exists an efficient variant of a Vickrey-Clarke-Groves mechanism based on dynamic menus of prices.

Chapter 3 (Dynamic revenue maximization with heterogeneous objects) is based on the same model, but considers the alternative goal of revenue maximization, assuming a finite deadline and a homogeneous Poisson process for customers' arrivals. The main insight is that it pays to focus on characterizing the implementable allocation policies. Then the revenue-maximizing pricing policy follows by applying variational arguments. Such policy allocates objects based on cutoffs such that prices at each point in time depend only on the size (but not on the composition) of the inventory. When the cost function is Schur-convex, this invariance allows one to determine the optimal size and quality composition of the inventory. Propositions 3 and 4 apply this conclusion to explain some empirical evidence about markdown sales.

Chapter 4 (The stochastic and dynamic knapsack model) keeps the focus on revenue maximization, but now assumes that agents have multi-unit demand with heterogeneous capacity requests. Under incomplete information, this turns it into a dynamic monopolistic screening problem with multidimensional values. The problem is solved in three steps: first, the implementable policies are characterized; second, (a relaxed version of) the revenue-maximization problem is solved; third, sufficient conditions are given to ensure that the solution of the relaxed version are implementable in the original problem.

Chapter 5 (Learning and dynamic efficiency) returns to the problem of finding an efficient allocation under one-unit demand, coupled with the intriguing assumption that there is parametric uncertainty about the distribution of agents' private values. The designer learns gradually about the distribution by observing the strategic choices of agents, whose actions generate informational spillovers. The main result is that efficient implementation is possible only when the impact of revealed information on today's values is higher than on future option values. Sufficient conditions for first-best implementation are obtained under Bayesian learning, as well as a characterization of the second-best. First-best implementation is also possible under two adaptive nonbayesian models that uniformly converge to the true distribution as the number of observations goes to infinity. 
Chapter 6 (Long-lived agents) makes agents long-lived and adds the new twist that they have private information about their own arrival and departure time. It collects five short variants. The first one assumes perishable objects to show that this leads to natural mechanisms to attain efficiency or revenue maximization under incomplete information. The second variant brings in non-perishable goods and explores the analogy with known models of search with recall. The efficient solution under complete information may be extended to incomplete information; when arrivals follow a newbetter-than-used renewal process, the technique applies also to revenue maximization. The third theme is efficiency in queue operations where the designer assigns priorities over a processing device and the costs of delay are private information. The fourth section considers dynamic analogs of the efficient Vickery-Clarke-Groves mechanism for queue management when agents have privately known deadlines and thus their private information evolves over time. Finally, looking at revenue maximization, it is shown how a monopolist who attains efficiency under such dynamic information arrival may apply dynamic screening to extract a higher revenue compared to waiting until all information arrives. 